\title{
La ópera Fidelio en España (1805-1936)
}

\author{
The opera Fidelio in Spain (1805-1936)
}

\author{
Francisco Manuel López Gómez \\ Universidad de Castilla-La Mancha \\ franmalogo@hotmail.com \\ ORCID: https://orcid.org/0000-0002-2988-2700
}

\section{RESUMEN}

El presente trabajo se centra en la recepción en España de la única ópera escrita por Beethoven, estrenada en el Teatro Real en noviembre de 1893 y puesta en escena en el Teatro del Liceo en enero de 1921. Para comprender los motivos por los cuales se ofrecieron únicamente dos representaciones de Fidelio en España con anterioridad a la Guerra Civil, se reflexiona sobre el estado previo en que se encontraba el teatro de ópera en este país y sobre el conocimiento de la figura de Beethoven y de su ópera en particular. Asimismo, tras una lectura exhaustiva de las fuentes hemerográficas y revistas conservadas, se analizan los acontecimientos relacionados con las dos representaciones mencionadas, la recepción por parte del público y las reflexiones estéticas surgidas.

Este artículo ofrece también información sobre distintos intentos frustrados de puesta en escena, así como datos relativos a las primeras retransmisiones de la ópera que llegaron desde Europa a España durante los años 20 y 30.

Finalmente, todo ello nos llevará a conclusiones respecto a la visión de Beethoven y de su ópera en España, que no llegó a ser aceptada por no adaptarse a los moldes de la escuela italiana y por la importancia que concedió al elemento orquestal, rasgo que dio lugar a distintas deliberaciones relacionadas con Wagner, el drama lírico, la música pura y la dramática.

Palabras clave: Beethoven, Fidelio, ópera en España, recepción musical, estética musical, crítica musical. 


\begin{abstract}
This work focuses on the reception of Fidelio in Spain before the Civil War (1936-1939). It was first performed in the Teatro Real in Madrid in November 1893, and later in the Teatro del Liceo in Barcelona in January 1921. The previous state of opera spectacle in Spain, as well as the knowledge of Beethoven and his opera, explains why only two performances of Fidelio were given in this period. Likewise, an exhaustive reading of the newspaper sources and the preserved journals offer important data about the events related to the two representations mentioned, their reception and aesthetic reflections about this opera.

This study also provides information about the several frustrated attempts at staging Fidelio and the first radio broadcasts of this opera that reached Spain from Europe during the 1920s and 30s.

Finally, it is possible to conclude that Fidelio was not accepted in Spain because it did not fit into the moulds of the Italian school. The other reason was the importance that the composer gave to the orchestral element, a feature which gave rise to various deliberations related to Wagner, lyrical drama, pure music and dramatic music.
\end{abstract}

Key Words: Beethoven, Fidelio, opera in Spain, musical reception, musical aesthetics, music criticism.

López Gómez, F. M. (2020). La ópera Fidelio en España (1805-1936). Cuadernos de Investigación Musical, (11, número extraordinario), pp. 92-112.

\title{
1. ANTECEDENTES: BEETHOVEN Y SU ÓPERA
}

La figura de Beethoven fue determinante para la aclimatación de la música instrumental en España durante el último tercio del siglo XIX, etapa en la que se asentaron y obtuvieron una gran acogida los conciertos públicos promovidos principalmente por la Sociedad de Conciertos y, más tarde, la Unión Artístico-Musical y la Sociedad Catalana de Conciertos. Sin embargo, el repertorio operístico ligado a los compositores del Clasicismo vienés no corrió la misma suerte; ni tan siquiera las obras escritas por Mozart, ya que después de los estrenos de Cosi fan tutte en Barcelona (1798), Le nozze di Figaro en Madrid (1802), y Don Giovanni de nuevo en Barcelona (1834), no volvería a programarse esta última hasta la década de los 60 y después lo haría de forma muy intermitente (López Gómez, 2016).

Los motivos deben buscarse en el monopolio que ejercieron en los teatros de ópera españoles las obras del romanticismo italiano ya desde comienzos de siglo, cuando se estrenaron la práctica totalidad de las óperas de Rossini, un monopolio postergado con el triunfo de Bellini, Donizetti y después Verdi. En definitiva, el gusto del público español se educó con la ópera italiana, de manera que las pocas ocasiones que tuvo de escuchar alguna ópera de Mozart la calificaba de "vieja" e "incapaz de conmover" (Masarnau, 5 de enero de 


\section{FRANCISCO MANUEL LÓPEZ GÓMEZ}

1835, p. 94). Por este motivo, no es de extrañar que, aún a mediados de siglo, se ignorase en España la existencia de Fidelio y su autoría, hasta el punto de que llegó a ser atribuida a Verdi (S/N, 11 de enero de 1852, p. 4). Únicamente en los círculos de intelectuales, compositores, profesores y entendidos se tenía noticia del Fidelio de Beethoven, como demostró Velaz de Medrano (30 de junio de 1852, pp. 3-4) cuando se lamentaba de que todavía no se conocieran ni siquiera las sinfonías del "autor de Fidelio". En este sentido, resulta paradójico pero común el uso en la prensa española, durante la segunda mitad del siglo, de la expresión "autor de Fidelio" para aludir a Beethoven, independientemente del contexto en que estuviera inserta, cuando su ópera fue completamente ajena al oído del público hasta el 8 de noviembre de 1893, fecha de su estreno en el Teatro Real ${ }^{1}$.

En esta misma línea, las primeras noticias respecto a la ópera del genio de Bonn llegaron únicamente a través de medios extramusicales. En 1846 la imprenta de Pablo Bustamante publicó en Madrid una traducción al castellano de la novela Paula Monti (1842) del francés Eugène Sue, y después también lo hizo la imprenta de Gómez Oro en Sevilla; más tarde, alcanzó gran difusión por aparecer en fascículos en El Clamor Público². En ella, varios personajes interpretan un aria de Fidelio y algunos pasajes de la obertura.

Tras este primer contacto indirecto, la creciente popularización de las sinfonías de Beethoven en España a lo de la década de los 60 despertó el interés por el compositor en los diletantes y la propia prensa, donde aparecieron varios ensayos biográficos en los que Fidelio desempeñaba un papel relevante, probablemente, por estar muchos de ellos tomados de los periódicos y revistas de París, donde se había puesto en escena recientemente. Entre ellos, destacó por su rigor y extensión el publicado por fascículos en El artista entre mayo y noviembre de 1867, que tomaba la información de varias fuentes de interés publicadas hasta la fecha tanto en francés como en alemán ${ }^{3}$. De esta forma, junto con otros datos biográficos y del resto del catálogo beethoveniano, proporcionaba la primera información de interés relativa a la composición de Fidelio: precedentes a la concepción de la ópera, origen del libreto y su traducción del francés, estreno desafortunado en Viena tras la invasión francesa, modificaciones y cortes relacionados con las anécdotas en casa del príncipe Lichnowsky y del dramaturgo Friedrich Treitschke, reposiciones posteriores, versiones de la obertura, y desazones que todo el proceso causó en Beethoven a raíz de su sordera (S/N, 30 de junio de 1867, pp. 26-29; y S/N, 7 de julio de 1867, pp. 35-37).

Representativa en este sentido fue también la aparición de los artículos de Victor Wilder en Le Ménestrel relativos a la juventud de Beethoven, traducidos y publicados con muy poco lapso temporal por la Revista europea de Madrid entre enero y febrero de 1880. En ellos

\footnotetext{
${ }^{1}$ Así, incluso en la época en que comenzaron a interpretarse las sinfonías del compositor por primera vez en España - con los Conciertos de Barbieri en los Jardines de Apolo durante el estío de 1866-, se hacía mención al "autor de Fidelio" (Cuenca, 15 de septiembre de 1866, pp. 1-3).

${ }^{2}$ El fragmento de la novela donde aparece la referencia a la ópera de Beethoven puede consultarse en Sue (22 de febrero de 1852, p. 1).

${ }^{3}$ Las fuentes utilizadas fueron: Biographische Notizen über Ludwig van Beethoven, publicadas por Franz Wegeler y Ferdinand Ries (Koblenz, 1838) y traducidas por Legentil; Beethoven et ses trois styles, publicada por Wilhelm von Lenz (París, 1852); Ludwig van Beethoven: Leben und Schaffen, escrito por Adolf Bernhard Marx (Berlín, 1859); Biographie von Ludwig van Beethoven, de Anton Felix Schindler (Múnich, 1860); Briefe Beethoven, de Ludwig Nohl (Stuttgart, 1865); y Drei und achtzig neu aufgefundene Original-Briefe Ludwig van Beethovens an den Eræherzog Rudolph, de Luwig Ritter von Kochel (Viena, 1865).
} 
se recogían, además de los datos publicados por El artista en 1867, los relativos a: la admiración del compositor por las obras líricas de Cherubini y Méhul; la historia y proceso de composición en los jardines de Schönbrunn; los bosquejos y correcciones de la partitura conservados en el cuaderno que poseía la familia Mendelssohn; el origen del libreto a partir de la obra de Bouilly y las otras versiones operísticas de Gaveaux y de Paër; las anécdotas con los artistas durante los ensayos con Seyfried; el cambio del título por recomendación del barón Braun; el estreno y la fría recepción con comentarios de la prensa de la época; el juicio positivo y análisis de la obra por parte de Berlioz en su obra $A$ Travers chants (1862) -que compara con el estilo lírico de Mozart y Gluck, entre otros-; y el propio análisis descriptivo y entusiasta del autor del artículo, especialmente el del coro de prisioneros -en él encuentra "el arte soberano, la inspiración abrasadora, el vuelo fulgurante del genio"- (Wilder, 5 de febrero de 1880, pp. 143-150; y Wilder, 20 de febrero de 1880, pp. 181-186). De gran interés son, además, las apreciaciones del crítico respecto al hecho de que Fidelio se hubiera puesto en escena en el Théâtre-Italien de París y todavía no se hubiera escuchado en la Ópera, en cuyo peristilo estaba colocada, paradójicamente, la estatua de Beethoven (Wilder, 20 de febrero de 1880, p. 184).

En cuanto al resto de España, en Barcelona no apareció un estudio centrado en la ópera beethoveniana hasta la publicación de una reseña por parte de Chavarri (1912), realizada a la monografía de Maurice Kufferath sobre la ópera, publicada en París ese mismo año. En ella, además de los datos constatados anteriormente, se incidía en la ambientación de la obra en Sevilla, la adaptación ulterior en una puesta en escena en París en 1860 donde se situaba la acción en el Milán del s. XV, la defensa de la obra original frente a las adulteraciones de Gevaert-que sustituyó las partes declamadas por recitativos-, y las crudas valoraciones del compositor D’Indy. Pero la reseña realizada por Chavarri no sólo se publicó en Barcelona, sino que salió a la luz también en ciudades como Bilbao (Chavarri, noviembre de 1912) y deducimos que lo haría en otros puntos geográficos de la Península, lo cual permitió que los lectores tuvieran un primer acercamiento a la obra, aún sin haberla escuchado fuera del círculo madrileño.

Como hemos comentado, durante la década de los 60 del s. XIX se produjo en España, tanto en la capital como en otras ciudades importantes, una verdadera aclimatación de los conciertos públicos, en los que la figura de Beethoven ocupó un lugar preeminente, tanto de sus sinfonías como de su música de cámara. Junto a este repertorio llegaron los primeros fragmentos de su ópera, y el primero en ofrecerse fue la obertura. En este caso, fue Barcelona el punto de la Península donde primero pudo escucharse - no se especifica la versión-, ya en 1867, en los Conciertos Clásicos celebrados en el Prado Catalán dirigidos por Juan Casamitjana (S/N, 16 de marzo de 1867, p. 3). A la ciudad condal sucedieron: la capital en 1869, donde la versión n. 3 de la obertura -la escrita por Beethoven para la versión de 1806fue presentada por primera vez por la Sociedad de Conciertos dirigida por Monasterio $(\mathrm{S} / \mathrm{N}$, 2 de mayo de 1869); y San Sebastián al año siguiente, donde se ejecutó en el Kursaal por la sociedad de artistas del teatro (S/N, 9 de noviembre de 1870, p. 4). Desde finales de los años 60 , la obertura se constituyó en parte del repertorio más recurrido de orquestas como la 


\section{FRANCISCO MANUEL LÓPEZ GÓMEZ}

Sociedad de Conciertos, de forma que estuvo presente en la mayoría de las temporadas, lo cual es muestra de su positiva recepción por parte del público.

En el terreno vocal, en Madrid se conocían ya en la década de los 70 algunos fragmentos de la ópera, gracias a la iniciativa de profesores como Baltasar Saldoni, que organizaba conciertos interpretados por sus alumnos en los que no sólo estaban presentes "trozos de óperas italianas", sino también fragmentos de Fidelio (S/N, 29 de abril de 1870, p. 3). Quizá el más conocido fue el aria de Leonora «Abscheulicher! Wo eilst du hin?», si bien apareció con mucho retraso, como sucedió con el caso de Barcelona, donde la encontramos programada en el Teatro Lírico y cantada por la soprano Blanc en 1896 -es decir, más de dos años después del estreno de la ópera en España- (S/N, 8 de marzo de 1896, p. 6), en el Palau de la Música Catalana en un concierto extraordinario del Orfeó Català interpretada por Bertrán (L., 12 de marzo de 1910, p. 159), o poco tiempo después en el mismo espacio por la soprano Felicia Hallama - procedente del Deutches Opernhaus de Berlín-, ya que constituía uno de sus mayores éxitos (S/N, 28 de febrero de 1913, p. 2). También la encontramos interpretada en La Coruña, en un concierto de la Sociedad Filarmónica organizado en 1909 e interpretada por América Montenegro, esposa del famoso violinista Andrés Gaos (S/N, 5 de febrero de 1909, p. 1).

\section{ANTECEDENTES: BEETHOVEN Y SU ÓPERA}

Por tanto, con la excepción del preludio, en España no se conoció la ópera de Beethoven hasta la década de 1890. Es probable que se hubiera contemplado poner en escena en el Teatro Real a finales de los 60, pues su empresario, el francés Charles Prosper Bagier, lo era también del Théâtre-Italien de París, donde estrenó Fidelio en 1869 (S/N, 26 de diciembre de 1869, p. 4). Sin embargo, tras ocho años en el cargo al frente del Real, lo abandonó en diciembre de 1867 (Turina, 1997, pp. 100-109). No obstante, es igualmente probable que Bagier no hubiera contemplado dicho estreno, dadas las preferencias del público del Real, educado completamente en la ópera italiana.

En cualquier caso, dado el éxito que alcanzaron las sinfonías de Beethoven en España el público madrileño llegó a solicitar en 1881 al entonces director musical del Real, Juan Goula, el estreno de Fidelio, "que es una vergüenza no se conozca en Madrid" (S/N, 13 de abril de 1881, p. 5). En efecto, la apertura a nuevos repertorios de ópera en España, aunque se produjo lentamente, fue cada vez más notoria, primero con las óperas de Meyerbeer ya en la década de los 50 y Gounod en los 60, y después con las de Wagner desde mediados de los 70 -nos referimos a Rienzi y Lohengrin, estrenadas en el Real en 1876 y 1881, respectivamente-. En este contexto, en 1889 se solicitaba de nuevo que se diera a conocer Fidelio o se volviera a presentar Don Giovanni de Mozart, en lugar de la tetralogía wagneriana, que era ya demandada por algunos sectores del público (S/N, 4 de noviembre de 1889, p. 1); y en 1891 volvía a retomarse la cuestión de por qué no se programaba a Gluck, Mozart, Weber y el Fidelio (Bleu, 27 de julio de 1891, p. 1). 
Sin embargo, la presencia todavía dominante de la ópera italiana y la indiferencia mostrada por el Real ante repertorio nuevo, ya fuese contemporáneo o clásico, seguía desencadenando reacciones que se traducían, en ocasiones, en artículos de tono sarcástico como el publicado en La Iberia en octubre de 1883. En él se nos relata de forma ingeniosa, bajo anonimato y con el objetivo de reseñar una representación de Aida dirigida por Goula, un supuesto sueño que tiene un abonado que ha llegado con tiempo a la función y se ha dormido en su palco. Rossini y Beethoven, que se dirigen al lugar indicado para observar desde el cielo dicha función de Aida en el Real, conversan de camino sobre la nueva temporada de dicho teatro; el segundo comenta que ha escuchado a Morales y Victoria afirmar que "iban a hacer un poco por el arte en aquel bendito teatro Real", ya que tenían pensado presentar Semiramide, Fidelio, y las óperas de Mozart, Cimarosa y Weber, entre otros, a lo que Rossini responde al ingenuo Beethoven aludiendo al negocio del arte y a la costumbre del público de asistir a la ópera no a escuchar música, sino a charlar, negociar y dejarse ver o, a lo sumo, "esperan el aria en la cual el tenor o la tiple destrozan mi música o la tuya” (S/N, 18 de octubre de 1883, p. 3).

En el contexto barcelonés sucedía lo mismo, y aunque, al parecer, se contempló programar Fidelio en el Liceo para 1891 (S/N, 30 de septiembre de 1890, p. 343), todavía a la altura de 1910 no se había puesto en escena en la ciudad condal. De ello se lamentaba el compositor y crítico Vicenç María Gibert, quien calificaba de vergüenza que no se conociera allí el Fidelio en Barcelona, "obra capital del teatro, mucho tiempo olvidada, pero a la que se hace hoy justicia en los principales escenarios de Europa".

Tras poco más de un mes de ensayos (S/N, 29 de septiembre de 1893, p. 3), el estreno en España de Fidelio tuvo lugar finalmente en el Teatro Real el 8 de noviembre de 1893, junto a óperas como La Gioconda, Lohengrin, Manon Lescaut, La Jolie fille de Perth, Tannhäuser, La Juive, Mefistofele, Los amantes de Teruel, Hamlet de Thomas y Die Meistersinger von Nürnberg, en lo que constituyó, por tanto, una temporada de notable interés. La ópera beethoveniana estuvo dirigida por Juan Goula e interpretada por Teresa Arkel (Leonora), Josefina Huguet (Marcelina), Emilio de Marchi (Florestán), Francesco Navarrini (Roque), Alfonso Mariani (Pizarro), Antonio Oliver (Joaquín), José Vivó y Fuster (prisioneros) (S/N, 13 de octubre de 1893 , p. 3), artistas algunos de los cuales habían cantado la obra en otros teatros europeos (S/N, 10 de octubre de 1893, p. 2). Al parecer, la ejecución fue buena y bien recibida por la crítica:

Difícilmente se ve ejecución tan cuidada como la de Fidelio, y quizá no sea posible un conjunto más homogéneo que el obtenido. Todos a porfía se han esmerado en sus papeles, y desde los coros hasta los cantantes y la orquesta, por igual merecen los plácemes de la crítica. [...] Débese esto en primer término al maestro Goula. Ensayó Fidelio con exquisito cuidado; no perdonó detalle; usó toda su diligencia hasta en los menores accidentes, y la dirección de la obra de Beethoven, si otros méritos no tuviera ya adquiridos, bastaría a darle fama de insigne director de orquesta (Guerra y Alarcón, 30 de diciembre de 1893, p. 187). 


\section{FRANCISCO MANUEL LÓPEZ GÓMEZ}

La Arkel cantó con seguridad la parte de Fidelio, siendo muy aplaudida en todas las piezas, especialmente en el aria del acto primero, que dijo con gran calor; la Huguet hizo una buena Marcelina; De-Marchi, en la difícil aria $A b$ ! Che oscurità! (tan difícil que el menor descuido puede producir un fracaso), rayó a gran altura, obteniendo muchos aplausos; Navarrini cantó a conciencia la importantísima parte de Rocco, hizo gala de su hermosa voz y fue el alma de todas las piezas en que intervino; y Mariani, en su parte de D. Pizarro, y Oliver, en la de Gioachino, contribuyeron al buen éxito de la ejecución (Allegro, 9 de septiembre de 1893, p. 3).

Acerca de la ejecución, es de interés notar que se interpretó como preludio, tal y como suele hacerse en la actualidad, la tercera obertura de las que Beethoven compuso para la ópera, conocida como Leonora núm. 4, precisamente porque no se había escuchado tampoco en Madrid, mientras que la segunda -o Leonora núm. 3 que, como hemos comentado, había sido ejecutada hasta entonces en numerosas ocasiones por la Sociedad de Conciertos- se reservó para el intermedio del segundo al tercer acto. Asimismo, destaca el hecho de que se ofreció en la versión italiana con recitativos, tal y como se representó por vez primera en el King's Theatre de Londres en 1832 (Sepúlveda, 14 de octubre de 1893, p. 1). El hecho de ofrecerla en italiano, con recitativos y subdividida en tres actos en lugar de los dos concebidos por Beethoven en su última versión no es de extrañar ${ }^{4}$, de nuevo, debido a la fuerte tradición italiana a la que hemos ya aludido, que constreñía las producciones alejadas de estos moldes y determinaba, por tanto, la traducción de cualquier ópera al italiano, su división en tres actos, y la imposibilidad de incluir partes habladas ${ }^{5}$.

Otro aspecto que llama la atención relativo a la ejecución fue la disposición de la orquesta "a la alemana”, descrita por Goula, quien se colocó:

En el centro de los profesores: a mi espalda las arpas, de frente todos los violoncellos, [con el fin de] tener muy a mi alcance todos aquellos instrumentos a quienes con más frecuencia hay que atender y dar entradas, para moverme, teniéndolos así, lo menos posible, y evitarme, si puedo, algunas censuras que me dirigen por mi extremada nerviosidad (Sepúlveda, 14 de octubre de 1893, p. 1).

Como puede suponerse tras los hechos analizados, el estreno fue precedido de una gran expectación en los amantes de la música de Beethoven, de modo que al iniciar el preludio algunos impusieron silencio "a los profanos que se atrevían a hablar siquiera en voz baja" (S/N, 9 de septiembre de 1893, p. 1), gesto que no era común. Precisamente, los fragmentos instrumentales de la obra, en este caso las oberturas, fueron los momentos más aclamados, hasta el punto de que tuvieron que repetirse ante los "aplausos estruendosos, frenéticos, [que] estalla[ron] en todos los verdaderos amantes del arte" (S/N, 9 de septiembre

\footnotetext{
${ }^{4}$ Sobre la versión definitiva de 1814 en dos actos, se operaría una división al primero de ellos después del terceto «Gut, Söhnchen, gut, hab immer Mut», para hacer así coincidir el inicio del segundo concebido por Beethoven con el "tercero", es decir, con el aria de Florestan «Gott, welch Dunkel hier».

${ }^{5}$ Por los dos primeros procesos pasaron, incluso, algunas de las óperas de Wagner ejecutadas en el Real.
} 
de 1893, p. 1). En efecto, el público admiraba la "virilidad prodigiosa" del lenguaje orquestal de Beethoven, así como su expresividad y el trabajo con el desarrollo de los motivos, "no emulado por nadie, ni a quien nadie ha osado acercarse" (S/N, 9 de septiembre de 1893, p. 1).

Sin embargo, el peso de la tradición, que veía al genio de Bonn como la culminación del lenguaje sinfónico y como compositor frustrado en el terreno operístico, condicionó el juicio del resto de la obra, a la sombra del genial Mozart, "un Mozart, más varonil, más enérgico, pero sin sus dulzuras y su variedad portentosa" (S/N, 9 de septiembre de 1893, p. 1). En esta línea, la importancia concedida a la orquesta, en detrimento del lirismo vocal, no sólo determinó que decayera el interés el público, a quien resultó un trabajo lánguido, sino que hizo resurgir el tema del drama lírico y de la supuesta tradición iniciada por Beethoven y culminada por Wagner con su Obra de arte total. Como es sabido, se trataba de un discurso estético bien desarrollado en Europa y alimentado por el propio Wagner, si bien no era ajeno en el panorama español, como demostró Arrieta, que ya en 1852 escribió:

\begin{abstract}
Quien se proponga escribir óperas y en vez de ser fiel intérprete de la poesía, la sacrifique para dar a la música esta o la otra forma, le aconsejamos que no escriba nunca para el teatro. Beethoven en su Fidelio, se muestra sinfonista colosal, y puede decirse que su ópera es una sinfonía en tres actos: las voces hacen un papel secundario, y la acción del melodrama está sometida continuamente al capricho del compositor (Arrieta, 14 de septiembre de 1852, p. 2).
\end{abstract}

Años antes del estreno en España, el presidente del Ateneo de Cádiz expresaba, en la misma línea, que Beethoven sólo había compuesto sinfonías, y en esta línea estaban concebidos no sólo sus cuartetos y sonatas, sino su misa y su ópera, que no es "sino una sorprendente sinfonía en dos actos, sinfonía que las voces tienen una parte muy secundaria como sujetas constantemente a la orquesta a la cual sirven más bien de acompañamiento" (S/N, 21 de diciembre de 1886, p. 1).

Tras el estreno en Madrid, Guerra y Alarcón (15 de diciembre de 1893), en la línea wagneriana, utilizó parte del análisis de Berlioz (1862) para construir un discurso en el que hablaba de varios leitmotive: los que aparecen después del aria de Pizarro en el primer acto, que se transforman en carácter -"en el recitado tiene acento dramático, en el adagio es sublime por su expresión, [y] lleno de gracia y de ternura, en el allegro seductor"- (p. 178), y el situado en el allegro consistente en cinco notas del acorde, si, mi, sol, si, mi, emitidas por las trompas.

Relacionada con la cuestión del drama lírico encontramos la peculiar distinción realizada por Bretón (25 de noviembre de 1893, pp. 54-55) entre música pura y música dramática. En la primera, de la cual sería claro ejemplo Fidelio, primaría la parte musical sobre el libreto, la forma sobre el contenido dramático. En la segunda, la música está subordinada al devenir de los acontecimientos y a los sentimientos de los personajes, que, por tanto, determinan el estilo, la forma, la estructura y todos los elementos de la partitura. Para el mismo autor (Bretón, 25 de noviembre de 1893, p. 54), el público “de buen gusto” podía 


\title{
FRANCISCO MANUEL LÓPEZ GÓMEZ
}

aceptar a finales del XIX "un cuarteto de Haydn con tanto placer como lo escuchara el aficionado de fines del pasado siglo", pero dicho público no soportaba, en cambio, el mismo estilo de música en el teatro de ópera, pues se trataba de música pura que no reflejaba el trasunto dramático. El primer acto de Fidelio es el que más adolecía de este calificativo:

\begin{abstract}
Causa admiración cómo tal coloso, en su segundo período, [...] muestre la timidez que observamos en la forma y procedimientos de la primera mitad del primer acto -que pudiera muy bien pasar por de Mozart- no vislumbrándose su personalidad hasta la patética Aria de Leonora, personalidad que adquiere cuerpo en el Coro de prisioneros, para llegar a la grandeza beethoveniana en todo el $2^{\circ}$ acto -división original- fuera del pueril y ordinario Final de la ópera. [...] [De su temperamento instrumental], el Aria de Florestán es buena prueba. Toda ella es hermosa, pero es mucho más grande en el preludio instrumental que en el resto (Bretón, 25 de noviembre de 1893, pp. 53-54).
\end{abstract}

Ya en 1913, Díaz Giles, presidente de la sección de literatura y música del Ateneo de Menorca, se pronunciaba del mismo modo cuando afirmaba que Beethoven reflejaba en su Fidelio su talento orquestal, pero que era incapaz de adaptarse a las exigencias de la escena "tal como la comprendemos después de Gluck, Mozart, Rossini y Meyerbeer" (Díaz Giles, abril de 1913, p. 113). En la misma línea se expresaban Pahissa (14 de enero de 1921, p. 9) y Alard (13 de enero de 1921, p. 13) tras el estreno de la ópera en el Liceo, especialmente en lo relativo al primer y último cuadros, donde observaban la "más estricta corrección en el lirismo". No obstante, para entonces ya comenzaban a apreciarse los números más sobresalientes a nivel dramático, como el coro de prisioneros y, en general, el primer cuadro del segundo acto, donde "resplandece toda la potencialidad del gran músico con frases de enorme fuerza emotiva" (Alard, 13 de enero de 1921, p. 13).

Teniendo en cuenta estos juicios, no es de extrañar que se bautizara como Fidelio la revista de música y teatros que comenzó a editarse en Madrid en 1902, cuyo propósito era, representativamente, contribuir modestamente [el subrayado es nuestro] a la ilustración musical y artística, además de proporcionar música "escogida, fácil y agradable" -en ocasiones, de nueva composición e inédita mediante los concursos que emitió ya desde enero de 1903 para premiar música de baile, obras para piano de pequeño formato y canciones o couplets- $(\mathrm{S} / \mathrm{N}$, 1 de enero de 1903, p. 2), calificativos todos que se habían atribuido a la ópera de Beethoven, la única teatral del quien entonces era considerado el que alcanzó "la cima más alta a que hasta ahora ha llegado el arte musical” (S/N, 1 de diciembre de 1902, p. 2).

En cualquier caso, el respeto a la figura del genio de Beethoven, mostrado a pesar de todo por la totalidad del público durante el estreno de Fidelio ${ }^{6}$, ocasionó disputas respecto a

\footnotetext{
6 "Fidelio no ha gustado en Madrid. Claro que este no gustar no se ha manifestado como si se tratara de una obra sometida por primera vez al fallo de nuestro público, o aunque ya sancionada por otros, susceptible aún de discusiones, con siseos y murmullos de desagrado, ni con silencio desdeñoso, ni con algaradas de la crítica, ni con juicios redondos y secos emitidos al salir del teatro, nada de eso. [...] Tenemos la suficiente erudición para saber que Fidelio es de Beethoven y que Beethoven es el rey de la música, y que una de las joyas de su corona es Fidelio".
} 
las valoraciones realizadas relacionadas con la pretendida incapacidad para el drama y para la composición vocal. Destacan, en este sentido, las apreciaciones emitidas por un crítico del periódico Elpelotari:

$[\ldots]$ Y como no podemos decir así en redondo que no nos gusta, $[\ldots]$ algunos creen que esa música no es de teatro; ¡Como si la misma música que pintó la naturaleza, y cantó la alegría, y expresó el amor a la inmortal amada, y descubrió al mundo las tempestades de aquel gran cerebro y aquel gran corazón que tenía Beethoven, no sirviera igualmente para describir y expresar los tormentos de un enterrado en vida, y el amor de una esposa fiel, y la cándida y simpática bellaquería de un carcelero ad usum! Y también ha habido quien ha dicho que Beethoven no sabía escribir para voces. [...] La obra me entusiasmó. Sólo por oír aquel coro de prisioneros se puede dar cualquier cosa. Y no hablemos del aria de Fidelio, y de la del delirio y del dúo de la fosa, [...] y del dúo de amor de los esposos. Créeme: son cosas hermosísimas, admirables. (Pipí [pseud.], 16 de noviembre de 1893, pp. 54-55).

A pesar de todo, como hemos podido apreciar la generalidad del público español no llegó a aceptar el lenguaje puro utilizado por Beethoven en gran parte de su ópera, ya descontextualizada estéticamente, pues, desinteresado por el arte sublime del compositor -como afirmaba el crítico de La publicidad, "un teatro no es Ateneo" (S/N, 21 de enero de 1921, p. 1)-, sólo aceptaba los dramas modernos o los ligados a la tradición italiana. Esta fría recepción, como hemos ya indicado, no fue ajena a la escena francesa, y, de hecho, fue ya detallada por Berlioz (1862) en los mismos términos:

Lo que va en detrimento de la música de Fidelio con el público parisino es la castidad de su melodía, el soberano desprecio del autor por el efecto sonoro cuando no está motivado, por los finales banales, por los períodos previstos; es la opulenta sobriedad de su instrumentación, la audacia de su armonía. [...] Las partes de la orquesta, las principales en algunos casos, las más oscuras en otros, contienen a veces el acento expresivo, el grito de la pasión, la idea finalmente que el autor no pudo dar a la parte vocal [el subrayado y la traducción del francés son nuestros] (pp. 72-73)7.

De hecho, se habló de volver a programar Fidelio en el Real para la temporada de 19031904, pero la iniciativa fue criticada por el anti-wagneriano Carmena y Millán, quien escribió una carta a Bleu para comentarle que la programación de la ópera de Beethoven supondría "una enemiga terrible contra los abonados a aquel coliseo, y su realización significaría condenarles a morir de tedio" (Carmena y Millán, 13 de agosto de 1903, p. 1). La contestación

\footnotetext{
7 “Ce qui nuit à la musique de Fidelio auprès du public parisien, c'est la chasteté de sa mélodie, le mépris souverain de l'auteur pour l'effet sonore quand il n'est pas motivé, pour les terminaisons banales, pour les périodes prévues; c'est la sobriété opulente de son instrumentation, la hardiesse de son harmonie. [...] Les parties de l'orchestre, les principales dans certains cas, les plus obscures dans d'autres, contiennent quelquefois l'accent expressif, le cri de passion, l'idée enfin que l'auteur n'a pas pu donner à la partie vocale".
} 


\title{
FrANCISCO MANUEL LÓPEZ GÓMEZ
}

de Bleu, wagnerista y defensor de la ópera del clasicismo -incluidas las de Mozart, que ya habían alcanzado gran éxito en Múnich-, se fundamentaba en la crítica del italianismo, que había convertido el Real en un "almacén de trastos viejos e infestos o en tenderete de feria" (Bleu, 17 de agosto de 1903, p. 1). También participó de la polémica Chavarri, posicionado con Bleu y que hizo notar cómo Fidelio formaba ya parte del repertorio de los teatros del centro y el norte de Europa (Chavarri, 21 de agosto de 1903, p. 2). Sin embargo, ni este proyecto ni el que pretendía ofrecerla en el mismo teatro en la temporada de 1913-1914 dirigida por Mancinelli (R. de C., 12 de mayo de 1913, p. 5) tuvieron éxito, pues no llegó a programarse.

En el terreno estético, existe otro factor a tener en cuenta y que influyó en la fría acogida de la ópera de Beethoven, un factor permeable a la tradición italiana: la concepción evolucionista de la historia del arte, especialmente arraigada en el siglo XIX y principios del XX. En este sentido se posicionaba Tomás Bretón, quien comentó lo siguiente, tras asistir al estreno:

\begin{abstract}
Parca en los efectos a que los maestros del día tienen acostumbrado al público, e inocente en extremo la acción [...] Mas por mucha que sea la cultura del público y por mucho cargo que se haga de la época en que la obra fue compuesta, tiene por fuerza que echar de menos el desarrollo y procedimientos musicales modernos, y más que nada, la acción, la intriga e interés dramáticos de las óperas contemporáneas. [...] En el teatro, no gusta el público de hacer concesiones; va a buscar emoción. De otro modo, aún durarían en la escena las obras maestras españolas del siglo XVII [...] El público es un monstruo voraz que pide sin cesar nuevo alimento, determinando inconscientemente su nivel, sus costumbres, nivel que ha de subir siembre, bajar, nunca (Bretón, 25 de noviembre de 1893, p. 54).
\end{abstract}

Como sucedió con la cuestión de la ópera española, cuyos trabajos nunca llegaron a formar parte del repertorio programado con asiduidad, para mantener en escena este tipo de obras la solución pasaba para algunos por la protección estatal. De lo contrario, la viabilidad empresarial se sustentaba únicamente en "dar gusto a los abonados" y prescindir de óperas no concebidas para el lucimiento de los cantantes, óperas, por otro lado, demandadas por ciertos sectores del público, capaces de "admirar las creaciones del genio" (Morphy, 20 de febrero de 1894, p. 1).

En el otro centro operístico por excelencia, el Liceo, en principio más permeable a las corrientes estéticas centroeuropeas, no se estrenó Fidelio hasta el 11 de enero de 1921 (S/N, 5 de septiembre de 1920, p. 7). Ya en 1915 el violinista Joàn Manén y el escritor Adrià Gual elevaron al ayuntamiento de Barcelona una instancia para que destinase una cantidad del presupuesto extraordinario a las representaciones de la ópera de Beethoven, pues ambos tenían proyectado ponerla en escena en la ciudad condal (S/N, agosto de 1915, pp. 252-253), si bien el proyecto no llegó a término. Fue finalmente Joan Mestres, empresario del Liceo, quien, tras su regreso de Alemania, contempló para la programación de 1920-1921 las óperas Tristán e Isolda, Tannbäuser y Fidelio, dirigidas por el reputado Otto Klemperer (S/N, 5 de 
septiembre de 1920, p. 7). La producción contó finalmente con Melaine Kurt (Leonora), Johanna Klemperer (Marcelina), John Glasser (Florestán), Emil Schipper (Don Pizarro) y Hanna Clemens (Jacquino) ${ }^{8}$ (S/N, 11 de enero de 1921, p. 6).

Como sucedió con el estreno en el Real casi tres décadas antes, el evento fue precedido de una publicidad considerable, de forma que se publicaba el libreto $(\mathrm{S} / \mathrm{N}, 11$ de enero de 1921, p. 6) y un estudio atrayente -incluía dos retratos de Beethoven hacia 1814- y extenso -además de los datos relativos al libreto y sus distintas adaptaciones operísticas, las distintas versiones de la obertura y de las arias de Leonora y Florestán, las modificaciones musicales y estructurales, y la recepción posterior en Europa, fue interesante la mención a los cambios realizados por Beethoven en el estilo vocal para la versión de 1814 con el fin de evitar florituras e italianismos-, tomado del estudio ya mencionado de Kufferath sobre la obra (Lliurat, 7 de enero de 1921, p. 9). Asimismo, se incidió en el hecho de que se ponía en escena para conmemorar el 150 aniversario del nacimiento de Beethoven (S/N, 13 de enero de 1921, p. 6), a pesar del pequeño desfase temporal.

Sin embargo, lo que más destacó fue la insistencia en subrayar que se trataba de la primera vez que Fidelio se ponía en escena en España - lo cual no era cierto, como hemos podido demostrar-, denominador común a todos los periódicos y medios de difusión de la época, y reflejo del olvido que había experimentado tanto la ópera de Beethoven como su puesta en escena de 1893. Así lo anunciaba La publicidad:

Rindiendo homenaje a la memoria del gran maestro, en el teatro del Liceo se pondrá por vez primera en escena, la única ópera de Beethoven. [...]. Nunca se había representado esta ópera en España, a pesar de que el asunto en el libreto es español (S/N, 11 de enero de 1921, p. 6).

Aunque contó con un elenco de artistas y director de origen alemán, llama la atención el hecho de que se cantó en italiano (S/N, 13 de enero de 1921, p. 6), dividida en tres actos y con los recitativos compuestos por Gevaert ${ }^{9}$, lo cual nuevamente muestra el peso de la tradición italiana en la escena española, aún a la altura de la década de 1920.

Al estreno en Barcelona acudió un público numerosísimo, entre el que podían encontrarse "muchos alemanes, [...] y aquí y allá algún caballero con la partitura abierta sobre las rodillas" (Ferrando, 25 de enero de 1921, p. 1). Sin embargo, al parecer la ejecución de los personajes principales no fue la deseada, ni por parte de las sopranos, que debutaban, ni

\footnotetext{
${ }^{8}$ No contamos con la información del cantante que desempeñó el papel de Rocco.

${ }^{9}$ La división en tres actos, no obstante, fue distinta a la concebida por Beethoven en su primera versión de 1804-5 y a la presentada en 1893 en el Teatro Real. Aunque no hemos podido obtener información sobre la modificación realizada a la estructura, la reseña a la puesta en escena elaborada por Lliurat nos da pistas al respecto: "Tal como el maestro Klemperer dividió la obra, nos resulta excesivamente largo el primer acto. Creemos que habría sido mejor [...] terminar el primer acto tras el delicioso terceto de Rocco, Leonora y Marcelina. Empezar el segundo acto con la pequeña marcha y terminar con el admirable coro de prisioneros. Todo lo demás, dejarlo para el tercer acto, dejando la obertura de Leonora núm. 3 antes de la gran escena final y durante la mutación" (14 de enero de 1921, p. 9).
} 
del tenor dramático o el barítono (S/N, 12 de enero de 1921, p. 7). Por su aparente imparcialidad, destaca la crítica realizada por Lliurat a la primera puesta en escena (la traducción del catalán es nuestra):

La ejecución del Fidelio en nuestro Gran Teatro del Liceo podemos decir que, con todo y sus grandes dificultades, ha sido bastante aceptable, aunque sin romper en absoluto como cabría, el modo tradicional de hacer las cosas en aquel espacio. El maestro Otto Klemperer tuvo buen cuidado de la orquesta y demostró haber estudiado la obra con detenimiento y con amor. Dirigió en todo momento la orquesta con seguridad y con ajuste. En la obertura Leonora núm. 3, que nos fue dada al final del segundo acto, sin embargo, abusó excesivamente del efectismo, desnaturalizando el pensamiento serio de Beethoven. [...] La señora Kurt (soprano) y el señor Glaser (tenor) en sus respectivas partes de Fidelio y Florestán, cantaron bien la obra, pero como actores no supieron llevar a la escena todo el relieve dramático que dio Beethoven a estos dos personajes. Muy justos también los otros intérpretes [...] (Lliurat, 14 de enero de 1893, p. 9) ${ }^{10}$.

En cuanto a la recepción, se repetían las mismas ideas respecto a la ópera de Beethoven: escaso valor otorgado a las partes vocales y poco interés dramático, centrado especialmente en la orquesta. A ello se refería Pahissa (14 de enero de 1921) cuando aludía a la dramaticidad de la música de Beethoven, verdadero personaje de su ópera y autor de un "conflicto inmaterial" (p. 9). Para dicho crítico, la diferencia entre el drama wagneriano y Fidelio radicaba en que el primero necesitaba constantemente de la evolución de la trama para conseguir el desarrollo musical, mientras que en el segundo es la música, con todos sus contrastes y atendiendo a su propia lógica y sus normas, la que refleja "los sentimientos, las pasiones, los cambios de la vida y del mundo". Según este razonamiento, por tal motivo Beethoven estuvo más inclinado a escribir música pura, mientras que Wagner se dedicó a la música dramática (Pahissa, 14 de enero de 1921). En este sentido, el libreto se convierte en una excusa no para el virtuosismo vocal, ni para la brillantez orquestal, sino para construir un drama musical. Beethoven, al fin y al cabo, "consideraba solamente dignas de la música las ideas nobles; amparado en esta idea de moralidad construye la gigantesca producción" (Frank, 1 de enero de 1921, pp. 28-29).

Para Lliurat, incluso, la obra de Beethoven no era una ópera, sino una obra de teatro, caracterizada y ensalzada con el lenguaje sinfónico del compositor; eso sí, "llena de pasión y heroísmo" (Lliurat, 12 de enero de 1921, p. 7). Para el crítico, con estas características, y debido a la personalidad de Beethoven, Fidelio estaba dotada de un "interés dramático

\footnotetext{
10 'L'execució del Fidelio en el nostre Gran Teatre del Liceu podem dir que, amb tot i les seves grans dificultats, ha estat força aceptable, encara que sense trencar en absolut, com caldría, els motllos tradicionals de fer les coses en aquella casa. El mestre Otto Klemperer tingué bona cura de l'orquestra i demostrà haver estudiat l'obra $\mathrm{amb}$ deteniment $\mathrm{i}$ amb amor. Conduí en tota ocasió l'orquestra amb seguretat i amb ajust. En l'Obertura Leonora núm. 3, que ens fou donada al final del segon acte, abusà, però, excessivament de l'efectisme, desnaturalitzant el pensament seriós de Beethoven. [...] La senyora Kurt (soprano) i el senyor Glaser (tenor) en llurs respectives parts de Fidelio i Florestan, cantaren bé l'obra, però com actors no saberen portar a l'escena tot el relleu dramátic que donà Beethoven a aquests dos personatges. Molt justos també els altres interpretadors $[\ldots] "$.
} 
excepcional"; además, constituía la primera obra que se podía calificar de "drama lírico", antecesora de la Obra de arte total wagneriana, y que sólo pudo nacer de un genio, el de la sinfonía:

La concepción del teatro lírico, tal como era aceptada y establecida en los tiempos de Beethoven y tal como lo es casi todavía hoy, a pesar de Wagner, Strauss y Debussy, no podía de ninguna manera imponer al genio de Beethoven el límite de sus proporciones. Era Beethoven, en todo caso, el que podía y debía sugerir e imponer unas nuevas proporciones al teatro. Estas proporciones había de crearlas con su música, sólo con su música, viva y fiel representación de su alma y de su formidable sentido de la emoción verdadera y de la belleza pura e inmortal. [...] Yo creo que, independientemente de su calidad musical y de su formidable valor técnico, Fidelio es el más humano, el más punzante de todos los dramas líricos: el más profundamente rico de emociones; el más vibrante de invención espiritual. Es el primer drama lírico que se manifiesta enteramente mediante la música, dando a ésta una significación poderosa y noble. Es solamente después del Fidelio que Wagner puede concebir y escribir su famoso Tristán e Isolda. Pero, así como el Tristán está concentrado todo él de una fuerte sensualidad, el Fidelio es desbordante y puro, todo él de una gran pureza. Esta virtud, esta pureza beethoveniana, que yo la considero muy trascendente y aleccionadora, es única en el teatro. [...] Beethoven, aportó al teatro, con esta obra, algo que es más que una orientación, algo que es más que una teoría. Aportó un manantial de emociones nuevas, de emociones redentoras, hijas directas y exclusivas de la música (Lliurat, 14 de enero de 1893, p. 9) $)^{11}$.

Sin embargo, para el crítico (Lliurat, 14 de enero de 1893), precisamente por estos motivos una obra de estas características difícilmente hubiera sido aceptada en los circuitos de ópera españoles.

\section{Fidelio en España hasta la Guerra Civil}

Para la temporada de 1922-23 del Liceo, Joan Mestres se propuso programar Fidelio junto al Anilo del Nibelungo, El caballero de la rosa, Las bodas de Figaro y otras propuestas interesantes, pero no se aprobó (S/N, 20 de abril de 1921, p. 14). Al parecer, un miembro de

\footnotetext{
11 "La concepció del teatre líric, tal com era acceptada i establerta en els temps de Beethoven i tal com és gairebé encara, malgrat Wagner, Strauss i Debussy, no podia de cap manera imposar al geni de Beethoven el limit de les seves proporcions. Era Beethoven, en tot cas el que podia i havia de suggerir 1 imposar unes noves proporcions al teatre. Aquestes proporcions ell havia de crearles amb la seva música, només amb la seva música, viva i fidel representació de la seva ànima i del seu formidable sentit de l'emoció veritable i de la bellesa pura i immortal. [...] Jo creo que, independentment de la seva qualitat musical i del seu formidable valor tècnic, Fidelio és el mes humà, és el més punyent de tots els drames lírics: el més profundament ric d'emocions; el més vibrant d'invenció espirituaul. Es el primer drama líric intern que es manifesta mitjançant la música, donant a aquesta una significació poderosa i noble. Es soláment després del Fidelio que Wagner pot concebre i escriure el seu famós Tristany i Isolda. Pero, així com él Tristany és concentrat i sensual tot ell d'una forta sensualitat, el Fidelio es desbordant i pur, pur tot ell d'una gran puresa. Aquesta virtut, aquesta puresa beethoveniana, que jo la considero molt transcendent y allisonadora, es única en el teatre. [...] Beethoven aportà al teatre, amb aquesta obra, quelcom que és més que una orientació, quelcom que és més que una teoria. Hi aportà una deu d'emocions noves, d'emocions redemptores, filles directes i excluusives de la música".
} 


\section{FRANCISCO MANUEL LÓPEZ GÓMEZ}

la junta del Liceo, "persona de alta posición", se quedó tranquilo al ver que, entre las óperas que se iban a ofrecer, no figuraba la de Beethoven, a quien calificó de "modernista" (S/N, 27 de octubre de 1922, p. 692).

Paralelamente a la producción del Liceo de 1921, también con motivo del 150 aniversario del nacimiento de Beethoven los escritores José Casado y Julio Pardo propusieron al Teatro de la Zarzuela dar al público algunas representaciones de Fidelio (S/N, 7 de noviembre de 1920, p. 17) en una versión en castellano realizada por ellos mismos (De'Lapi, 4 de enero de 1927, p. 4), una propuesta que fue tan bien recibida que se tenía previsto estrenarla en enero de 1921, interpretada "por reputados artistas de ópera, con una orquesta de 80 profesores y una masa coral de 300 voces" (S/N, 8 de diciembre de 1920, p. 4). Sin embargo, el proyecto no pudo llevarse a cabo, ni tampoco uno similar pensado para el centenario de 1927, sobre la versión castellana de los mismos Casado y Pardo (S/N, 19 de enero de 1927, p. 16). Así, a pesar de que para esta última producción -y para la de la música incidental Las ruinas de Atenas - la Masa Coral de Madrid llegó a ensayar los coros, esta hubo de suspenderse, como indicó el propio director del coro, Rafael Benedito, "por carecer de medios pecunarios [sic] para llevarla a efecto con toda la dignidad artística que requiere en cuanto a solistas, decorado, misé en scene, orquesta, etc." (Benedito, 22 de febrero de 1927, p. 4), y porque, al parecer, la traducción al castellano realizada no se adecuaba métricamente a la música de Beethoven.

Para el centenario del fallecimiento del compositor, el único espectáculo en el que estuvo presente su ópera tuvo lugar a finales del año en el teatro del Círculo de Bellas Artes, donde los alumnos del colegio de San Isidoro ofrecieron un interesante programa, que incluía lectura de poesía, exposición de pintura, y la interpretación de distintas composiciones, entre las que destacó "música de Fidelio", dirigida por el propio Rafael Benedito (S/N, 29 de diciembre de 1927, p. 2), quien aprovechó, así, el esfuerzo dedicado a un trabajo sin frutos para cumplir con su deseo de homenajear a Beethoven.

A pesar de los esfuerzos infructuosos por producir Fidelio en España para conmemorar el centenario del fallecimiento del compositor, esta fecha coincidió con las primeras retransmisiones registradas de la ópera, llegadas a la Península desde distintos teatros europeos que sí tuvieron ocasión de programarla. Así, el mimo mes de marzo -en que se cumplía dicho centenario-, se retransmitía una conferencia desde Hamburgo titulada "Fidelio y la ópera alemana”, previa a la retransmisión de la ópera desde Londres $(\mathrm{S} / \mathrm{N}, 20$ de marzo de 1927, p. 13); cinco días después -el día 27- se volvía a emitir por radio desde Múnich, en su versión final en dos actos (S/N, 27 de marzo de 1927, p. 13); y el 31 de marzo se retransmitía desde Viena (S/N, 31 de marzo de 1927, p. 1), puesta en escena como colofón de la celebración del centenario (Pujol, 1927, pp. 113-129).

Desde entonces y hasta la guerra civil española, aunque Fidelio no estuvo presente en los teatros, sí que se pudo escuchar por radio -teniendo presente que a este medio podría acceder una parte mínima de la población- retransmitida desde lugares como: Múnich, el 19 de mayo de 1929 (S/N, 18 de mayo de 1929, p. 11); Langenberg, el 11 de julio de 1929, cuya audición se aconsejaba "a las muchachas estudiantes" (S/N, 6 de julio de 1929, p. 19); 
Leipzig, el 16 de marzo de 1930 (S/N, 16 de marzo de 1930, p. 10); Berna, el 19 de septiembre de 1930 (S/N, 13 de septiembre de 1930, p. 21); Hamburgo, los días 31 de octubre y 9 de noviembre de 1930 (S/N, 25 de octubre de 1930, p. 21; y S/N, 8 de noviembre de 1930, p. 11); Múnich, el 6 de enero de 1931 (S/N, 3 de enero de 1931, p. 16); Gleiwitz, con la producción de Génova el 17 de septiembre de 1931 (S/N, 12 de septiembre de 1931, p. 17); Dresde, producida en Salzburgo el 31 de agosto de 1932 (S/N, 27 de agosto de 1932, p. 17); Argel, los días 7 y 15 de mayo de 1933 (S/N, 7 de mayo de 1933, p. 2; S/N, 13 de mayo de 1933, p. 2); Bruselas, el 9 de mayo de 1933 (S/N, 9 de mayo de 1933, p. 2); Langenberg, el 4 de junio de 1933 (S/N, 4 de junio 1933, p. 2); Estrasburgo, producida en Salzburgo bajo la dirección de Richard Strauss el 29 de julio de 1933 (S/N, 22 de julio de 1933, p. 23); Mühlacker, producida en Berlín el 14 de enero de 1934 (S/N, 13 de enero de 1933, p. 10); París, producida en Salzburgo el 28 de julio de 1934 (S/N, 21 de julio de 1934, p. 25); Múnich, el 20 de septiembre de 1934 (S/N, 15 de septiembre de 1934, p. 22); Bucarest, el 11 de abril de 1935 (S/N, 6 de abril de 1935, p. 25); Frankfurt, el 12 de mayo de 1935 (S/N, 11 de mayo de 1935, p. 20); Praga, el 15 de noviembre de 1935 (S/N, 9 de noviembre de 1935, p. 27); y desde la Unión Radio Madrid, Barcelona, Valencia y Sevilla -junto a las principales emisoras europeas-, producida en Salzburgo el 31 de agosto de 1935 bajo la dirección de Arturo Toscanini (S/N, 24 de agosto de 1935, p. 3).

\section{Conclusiones}

Hasta finales de la década de 1860, existía en España un desconocimiento generalizado acerca de la ópera escrita por Beethoven. La primera toma de contacto la tuvo el público exclusivamente con la obertura, en este caso la Leonora $n^{0} 3$, interpretada con asiduidad por la Sociedad de Conciertos, que dio a conocer el catálogo sinfónico del compositor. Junto a este referente sonoro, se dieron a conocer datos biográficos del compositor y relativos a la creación, recepción y estilo de Fidelio, tomados principalmente de la prensa parisina -debido a las puestas en escena de la ópera durante dicha década- y de los estudios que se publicaron y difundieron tanto en Francia como, especialmente, Alemania.

El triunfo creciente en España de las sinfonías de Beethoven desembocó un interés y curiosidad por su obra dramática, pero serán necesarias dos décadas de solicitudes a distintos empresarios del Real para que se pusiera en escena, hasta que finalmente se estrenó el 8 de noviembre de 1893, dirigida por Juan Goula e interpretada por artistas con experiencia en los papeles de los protagonistas. El enorme peso de la tradición operística italiana en España determinó la adaptación de la ópera, que quedó estructurada en tres actos, cantada en italiano y con los recitativos compuestos por Gevaert.

A pesar de ello, como sucedió con el público parisino - tal y como nos relata Berlioz (1862)-, tanto el que asistió al estreno en el Real como el del Liceo recibió fríamente una ópera que renunciaba al culto vocal y al efectismo sonoro banal, al que todos estaban acostumbrados. De hecho, los fragmentos que más éxito obtuvieron fueron los puramente orquestales (en este caso, las oberturas de Leonora $n^{\circ} 4$ y $n^{\circ} 3$, que se ubicaron en el preludio y como introducción al tercer acto, respectivamente). 
En efecto, lo que admiraba el público de Beethoven era su virilidad y su genialidad en el trabajo con los motivos musicales. Sus logros inigualables en el terreno sinfónico quedaron reflejados en el tratamiento orquestal de su ópera, hasta tal punto que, a juicio de la crítica y de algunas personalidades musicales, el verdadero drama lo constituía únicamente la música. Esta característica dio lugar a distintas reflexiones sobre la música pura, que, llevada al teatro, no era bien aceptada por el público, acostumbrado a finales del siglo, por un lado, al virtuosismo vocal de la escuela italiana y, por el otro, a las óperas construidas sobre lo que Bretón denominaba música dramática, que tenía su mayor exponente en Wagner y cuya forma y contenido dependían del texto. No obstante, lo que para unos era música pura llevada a la escena, para otros como Pahissa, por el significado del que estaba impregnada la parte orquestal, se trataba del primer drama lírico, antecedente de la obra wagneriana.

En definitiva, la fría acogida que tuvo la ópera beethoveniana en España, que no encontró un hueco entre la fuerte tradición italiana existente y el drama wagneriano, determinó que únicamente se programasen dos representaciones hasta la Guerra Civil, hasta el punto que pronto fueron olvidadas e, incluso, ignoradas, de modo que el único medio por el que se pudo escuchar esta obra, desde el centenario del fallecimiento del compositor, fue a través de retransmisiones radiofónicas venidas de Europa.

\section{BIBLIOGRAFÍA}

Alard (13 de enero de 1921). Liceo: Fidelio. El diluvio, p. 13.

Allegro (9 de noviembre de 1893). En el teatro de la Ópera: Fidelio. El País, p. 3.

Arrieta, E. (14 de noviembre de 1852). Revista musical: Vincenzo Bellini. La Nación, pp. 1-2.

Benedito, R. (22 de febrero de 1927). ¿Qué debe hacerse en Madrid para celebrar el centenario de Beethoven?. El heraldo de Madrid, p. 4.

Berlioz, H. (1862). A travers chants: études musicales, adorations, boutades et critiques. París: Michel Lévy Frères, libraires éditeurs.

Bleu, F. (27 de julio de 1891). El verano musical. El heraldo de Madrid, p. 1.

Bleu, F. (18 de agosto de 1903). El Teatro Real: Sr. D. Luis Carmena y Millán. El heraldo de Madrid, p. 1.

Bretón, T. (25 de noviembre de 1893). Fidelio de Beethoven, en el Teatro Real. Boletín musical, pp. 53-56.

Carmena y Millán, L. (13 de agosto de 1903). Carta abierta para el Sr. D. F. Bleu. El heraldo de Madrid, p. 1. 
Chavarri, E. L. (21 de agosto de 1903). Crónica musical: el supercrítico Sr. Carmena. El globo, p. 2 .

Chavarri, E. L. (1912). Fidelio, de L. van Beethoven, per Maurice Kufferath [reseña]. Revista musical catalana, 106, pp. 306-311.

Chavarri, E. L. (noviembre de 1912). Cómo escribió Beethoven su Fidelio y la vida de esta ópera [reseña]. Revista musical (Bilbao), 11, pp. 270-272.

Cuenca, V. (15 de septiembre de 1866). Conciertos en los Jardines de Apolo bajo la dirección del señor Barbieri. El artista, pp. 1-3.

De'Lapi, F. (4 de enero de 1927). Castillos en el aire: el centenario de Beethoven. El heraldo de Madrid, p. 4.

Díaz Giles, F. (abril de 1913). Beethoven y sus sinfonías. Revista de Menorca. Ciencias, artes y letras, pp. 113-116.

Ferrando, E. M. (25 de enero de 1921) Crónicas catalanas. Estreno de una ópera de Beethoven. La correspondencia de Valencia, p. 1.

Frank. (1 de enero de 1921) Fidelio. La academia de Calasancia, pp. 27-30.

Gibert, V. M. de. (1910). Julien Tiersot: Gluck. De la colecciò Les Maîtres de la Musique. Alcan, París [reseña]. Revista Musical Catalana, 80, pp. 238-239.

Guerra y Alarcón, A. (15 de diciembre de 1893). El Fidelio de Beethoven, II: el libro y la música. Ilustración musical hispano-americana, pp. 177-178.

Guerra y Alarcón, A. (30 de diciembre de 1893). El Fidelio, de Beethoven. III: el éxito y la ejecución. Ilustración musical hispano-americana, pp. 186-187.

L. (12 de marzo de 1910). Música: Orfeó Catalá. La Cataluña, p. 159.

Lliurat, J. (7 de enero de 1921). Fidelio, de Beethoven. La veu de Catalunya, p. 9.

Ll[iurat], J. (12 de enero de 1921). Teatres: Gran Teatre del Liceu, Fidelio (I). La veu de Catalunya (ed. tarde), p. 7.

Ll[iurat], J. (14 de enero de 1921). Teatres: Gran Teatre del Liceu. Fidelio (III). La veu de Catalunya (ed. tarde), p. 9.

López Gómez, F. M. (2016). La recepción de la obra lírica de Mozart en Madrid en la segunda mitad del siglo XIX. En P. Capdepón y J. J. Pastor (Eds.). Mozart y España: estudios y recepción musical, pp. 107-136. Vigo: Academia del Hispanismo. 


\section{FRANCISCO MANUEL LÓPEZ GÓMEZ}

Masarnau, S. (5 de enero de 1835). Don Juan [III]. El artista, p. 94.

Morphy, G. (20 de febrero de 1894). A propósito de la representación de Falstaff de Verdi, en el Teatro Real. La correspondencia de España, p. 1.

Pahissa, J. (14 de enero de 1921). Teatro Liceo: Fidelio. La publicidad (ed. mañana), p. 9.

Peña y Goñi, A. (9 de noviembre de 1893). Teatro Real: Fidelio. La época, pp. 2-3.

Pipí [pseud.] (16 de noviembre de 1893). Elpelotari en los teatros. El pelotari, pp. 54-55.

Pujol, F. (1927). La conmemoració del Centenari de la mort de Beethoven a Viena. Revista musical catalana, 282, pp. 113-129.

Sepúlveda, E. (14 de octubre de 1893). Madrid, 1893: la ópera Fidelio. El día p. 1.

R de C. (12 de mayo de 1913). Del Teatro Real: la temporada de invierno; un «venticello». La correspondencia de España, p. 5.

S/N. (11 de enero de 1852). Teatros estrangeros [sic.]. Correo de los teatros, p. 4.

S/N. (2 de mayo de 1869). Teatro y Circo de Madrid (antes del Príncipe Alfonso). Diario oficial de avisos de Madrid, p. 4.

S/N. (26 de diciembre de 1869). Teatros, La Iberia, p. 4.

S/N. (29 de abril de 1870). Crónica local. El Menorquín, p. 3.

S/N. (9 de noviembre de 1870). Noticias generales. La época, p. 4.

S/N. (13 de abril de 1881). Miscelánea. Crónica de la música, p. 5.

S/N. (18 de octubre de 1883). Los espectáculos. Teatro Real, inauguración: pesadilla de una noche de ópera. La Iberia, p. 3.

S/N. (21 de diciembre de 1886) Beethoven. La palma de Cádir, p. 1.

S/N. (4 de noviembre de 1889). Artes y letras. El Isleño, p. 1.

S/N. (30 de septiembre de 1890). España. Ilustración musical hispano-americana, p. 343.

S/N. (29 de septiembre de 1893). Noticias del Teatro Real. La correspondencia de España, p. 3.

S/N (10 de octubre de 1893). Noticias del Teatro Real. La correspondencia de España, p. 2.

S/N. (13 de octubre de 1893). Entre bastidores: Teatro Real. El liberal, p. 3.

S/N. (9 de noviembre de 1893). Teatro Real: Fidelio de Beethoven. La Correspondencia de España, p. 1.

S/N. (8 de marzo de 1896). Croniquilla general. El diluvio, p. 6. 
S/N. (1 de diciembre de 1902). Beethoven. Fidelio, p. 2.

S/N. (1 de enero de 1903). Concursos de Fidelio. Fidelio, p. 2.

S/N. (5 de diciembre de 1909). Sociedad Filarmónica: el segundo concierto Gaos. El noroeste, p. 1.

S/N. (28 de febrero de 1913). Teatros. La publicidad, p. 2.

S/N. (agosto de 1915). Instancies diverses. Revista musical catalana, 140, pp. 252-253.

S/N. (5 de septiembre de 1920). La próxima temporada teatral: en el Liceo. La publicidad, p. 7.

S/N. (7 de noviembre de 1920). Informaciones y noticias teatrales: Fidelio. ABC Madrid, p. 17.

S/N. (8 de diciembre de 1920, p. 4). Los teatros: Fidelio. El liberal, p. 4.

S/N. (1 de enero de 1921). Próxima solemnidad artística en Madrid: el Fidelio de Beethoven. La época, p. 6.

S/N. (11 de enero de 1921). El aniversario de Beethoven: estreno de Fidelio. La publicidad, p. 6.

S/N. (12 de enero de 1921). De Barcelona: Liceo, Fidelio. La publicidad (ed. mañana), p. 7.

S/N. (13 de enero de 1921). De Barcelona: una fiesta musical en el Liceo. La libertad, p. 6.

S/N. (21 de enero de 1921). Gran Teatro del Liceo: la última de Fidelio. La publicidad (ed. Noche), p. 1.

S/N. (20 de abril de 1921). Resumen de la temporada del Liceo. El diluvio, p. 14.

S/N. (27 de octubre de 1922). A cau d'orella. La esquella de la torratxa, pp. 691-692.

S/N. (19 de enero de 1927). El centenario de Beethoven en Madrid. El diluvio, p. 16.

S/N. (20 de marzo de 1927). Emisoras extranjeras. Ondas, p. 13.

S/N. (27 de marzo de 1927). Emisoras extranjeras. Ondas, p. 9.

S/N. (29 de diciembre de 1927). Fiesta infantil. La libertad, p. 2.

S/N. (18 de mayo de 1929). Emisoras extranjeras. Ondas, p. 11.

S/N. (6 de julio de 1929). Nuevas longitudes de onda. Ondas, p. 19.

S/N. (16 de marzo de 1930). Radiotelefonía. La libertad, p. 10.

S/N. (19 de septiembre de 1930). Emisoras de Unión Radio. Ondas, p. 21. 


\section{FRANCISCO MANUEL LÓPEZ GÓMEZ}

S/N. (8 de noviembre de 1930). Emisoras de Unión Radio. Ondas, p. 11.

S/N. (3 de enero de 1931). Emisoras de Unión Radio. Ondas, p. 16.

S/N. (12 de septiembre de 1931). Extranjero. Ondas, p. 17.

S/N. (27 de agosto de 1932). Extranjero. Ondas, p. 17.

S/N. (7 de mayo de 1933). La radio. Región. Diario de la mañana, p. 2.

S/N. (9 de mayo de 1933). La radio: programa para hoy. Región. Diario de la mañana, p. 2.

S/N. (13 de mayo de 1933). La radio. Región. Diario de la mañana, p. 2.

S/N. (4 de junio de 1933). La radio. Región. Diario de la mañana, p. 2.

S/N. (22 de julio de 1933). Extranjero. Ondas, p. 23.

S/N. (13 de enero de 1933). Extranjero. Ondas, p. 10.

S/N. (2 de marzo de 1934. Noticias: ciclo Beethoven. El heraldo de Madrid, p. 14.

S/N. (21 de julio de 1934). Extranjero. Ondas, p. 26.

S/N. (15 de septiembre de 1934. Extranjero. Ondas, p. 22.

S/N. (6 de abril de 1935). Programas extranjeros. Ondas, p. 25.

S/N. (11 de mayo de 1935). Programas extranjeros. Ondas, p. 20.

S/N. (24 de agosto de 1935). Festivales en Salzburgo: Fidelio, ópera de Beethoven. Ondas, p. 3 .

S/N. (9 de noviembre de 1935). Programas extranjeros. Ondas, p. 27.

Sue, E. (22 de febrero de 1852). Paula Monti, por Eugenio Sue. Segunda parte, capítulo IV: Intimidad. El clamor público, p. 1.

Wilder, V. (5 de febrero de 1880). Beethoven, III: Leonora-Fidelio. Revista europea, pp. 143-150.

Wilder, V. (20 de febrero de 1880). Beethoven (continuación). Revista europea, pp. 181-186.

Fecha de recepción: 22/11/2020

Fecha de aceptación: 03/12/2020 